\title{
Tense and aspect in Sranan
}

PIETER A. M. SEUREN

\section{Abstract}

Sranan is the main Creole language of Surinam (formerly Dutch Guyana). Its tense and aspect system is, though similar to, not identical with that of Guyanese or Jamaican. In this paper, a detailed attempt is made not only at describing the facts of the language, but also at giving rules that generate the correct forms with the correct meaning. The rule system is basically transformational, though the importani rules are morphophonemic. The system takes as underlying forms so-called 'shallow structures', which are semantically transparent in the sense that they reflect in a regular way a particular semantic analysis of tense and aspect. As regards tense, the 'double tense' analysis is applied, by which every verb form is preceded by two tenses, a deictic first tense (present or past), and an existentially quantifying second tense. This latter tense quantifies over either moments or durations of time. We thus get structures reading, e.g. 'At that past time there was a duration d such that "John sleep" is true at $d$ '. The aspectual difference between durative and momentary is accounted for by the difference in quantification: when the second tense quantifies over durations, the main verb becomes durative; when it quantifies over moments, the verb becomes momentary, i.e. non-durative. It then appears that a surprisingly simple rule system yields the correct forms from the postulated underlying forms.

Apart from a treatment of tense and aspect, a description is also given of the complexities of the copula verb (BE) in Sranan. Although, strictly speaking, this is a separate topic from tense and aspect, the copula verb is intricately interwoven with the phenomena of tense and aspect, and its treatmeni completes the picture.

In the description, account is taken of two varieties of the language, System $A$ which is the representative variety, and System $B$, which is spoken mainly by adolescent males in the capital. It results that only minute changes in the rul system are needed to account for the different sociolects. Within 
System $A$, there is one subvariety (regarding the simple past with or without ben). This difference is accounted for by inverting the order of the first two spelling rules, $\mathrm{S}-1$ and $\mathrm{S}-2$.

Furthermore, the rule system (as it varies between System A and System $B$ ) is presented in two different guises. First, it is formulated with the tense and aspect elements $\mathrm{e}$, ben and o as particles. Then, the description is reformulated with these elements as (auxiliary) verbs. It results that the formulations differ only minimally, and that the latter formulation is marginally simpler. The issue is relevant in connection with current debates regarding the status of auxiliary elements.

Finally, a literary sample text is presented and analysed as to the uses of tense and aspect. ${ }^{1}$

\section{Introduction}

Sranan, the main Creole language of Surinam, is increasingly being studied professionally by linguists, both Creolists and theoretical linguists. And with good reason: apart from the fact that improved knowledge of the structure of the language, its history, the conditions and varieties of its use, may be of assistance to the Sranan speaking community on the way towards full emancipation of the language, ${ }^{2}$ it also has some very interesting features from the point of view of theoretical linguistics. This paper is devoted to one particularly interesting chapter in the grammar of Sranan, the verbal system with its tenses and its aspects.

Sranan speakers themselves as well as those who have tried to learn the language later in life are aware of the complications brought about by the particles $e$, ben and $o$, which together establish a very elegant system of tenses and aspects. In the past, this system has been the object of systematic linguistic study by Voorhoeve $(1957 ; 1962)$, apart from a recent attempt by the present author (Seuren, 1981a). Although this study owes much to Voorhoeve's work, it is totally different in method, approach, and results. I shall not give a comprehensive discussion and criticism of Voorhoeve's work, but rather limit myself to occasional comments. A full discussion would take up considerable space and might distract from the purpose of this paper, which is to provide an analysis and a description of the verbal system of Sranan in the light of present-day theory and knowledge.

The tense and aspect systems of related Caribbean Creoles, in particular Jamaican Creole and Guyanese Creole, have been studied by a variety of authors, e.g. Bailey, 1966; Bickerton, 1975; Mufwene, 1980. Although the points of comparison with Sranan are non-trivial, there are nevertheless 
important differences. As was already clear to Schuchardt (1914: xiv), the Creole languages of Surinam, including Sranan, occupy an exceptional position among Creole languages in general, and the English-based Caribbean Creole languages in particular. This position of exception is due, mainly, to the fact that Sranan, though English-based as a language (the English dominated the colony from 1651 until 1667), was spoken in a Dutch dominated country for more than three centuries: Surinam remained Dutch until its independence in 1975. Consequently, a linguistic continuum, as described by Schuchardt (1914: viii) and later in greater detail, by DeCamp (1971) and others, could not develop in Surinam: there was, and has always remained, a clearcut distinction between Dutch and Sranan. Only in isolated lexical cases of Dutch-based lexical items do we find something approaching a phonological continuum between a basilectal Sranan pronunciation and an acrolectal Surinam-Dutch pronunciation (e.g. the basilectal word kolu ('guilder'), with an acrolectal / $\chi œ 1 \% /$, corresponding to the Surinam-Dutch pronunciation of the Dutch word guiden - cp. Eersel, 1971: 321). But there is nothing like a continuum of the kind found in British-dominated (ex-)colonies.

A further reason for the relatively exceptional character of Sranan vis- $\dot{a}-$ vis the related English-based Creoles comes from later linguistic admixtures. Though English-based in principle, Sranan has a notable stock of Dutch words, for obvious reasons, and also a large number of Portuguese, or Spanish-Portuguese words. These are traceable in part to Portugueseowned plantations in Surinam, originating from a settlement of Portuguese speaking Jews in the second half of the 17th century.

We find, moreover, a distinctly stronger African element in Sranan, compared to the other Creoles (Schuchardt, 1914: xxvii). And if Voorhoeve (1973) is right, the African heritage included a Portuguesebased Pidgin spoken along the West-African coast as early as the 16th century, which may be another, earlier source of Spanish-Portuguese words in Sranan. A process of relexification would then be responsible for the predominantly English character of the language or languages in question. An example of a likely 'originally' Portuguese word in Sranan is $k b a$ or kabá, from Portuguese acabar or acabado (acabão), meaning 'finish'. This word is found in the neighbouring Guyanese Creole as don, from English done (see Note 5).

In any case, the differences between Sranan and the other English-based Creoles in the Caribbean are sufficiently distinct for a separate description of the Sranan verbal system to be warranted. I shall, therefore, not discuss in any detail the works devoted to tense and aspect in the other languages. As has been said earlier, the facts of Sranan are definitely not the same as those of Guyanese, or of Jamaican, Creole. Regarding tense and aspect, I 
maintain that although Mufwene may be right in concluding that in Jamaican Creole, and Guyanese Creole too, the notion of "aspect" seems to have primacy over the notion of "tense", the opposite is the case in Sranan. In fact, certain (recent) varieties in Sranan tend to eliminate the role of aspect more and more, in favour of tense, as will be demonstrated below (System B). The obvious hypothesis is that in Sranan aspect used to dominate over tense until, maybe, a century ago, but that more recent developments tend to favour tense more than aspect. I shall refrain, however, from developing this hypothesis in any detail.

One of the main difficulties in trying to come to terms with tense and aspect in Sranan, as Voorhoeve also found, is the problem of getting access to the facts. This is due to a number of factors. First, Sranan, like every other language, is not a monolithic whole. On the contrary, there is a great deal of internal variation and of development in progress, clearly reflected in the verbal system. Secondly, the language suffers from social disrespect: it is still very common to find parents actively discouraging the use of Sranan by their children and encouraging the use of Dutch, that being considered the language of success and career. In the schools, moreover, Dutch is still the only medium language permitted, in spite of the fact that Surinam became independent in 1975. Apart from many other obvious educational disadvantages, one very noticeable result is a strong feeling of linguistic insecurity with many native speakers of the language. In practice, many speakers use a language that is Sranan in structure and grammar but highly infected with unadapted Dutch lexical items (Koefoed and May, 1980). True, Sranan often lacks words needed in a particular discourse, and the regular procedure in such cases is to fall back on Dutch. But the language one very often hears contains far more Dutch words than is necessary. Fortunately, there is a growing number of speakers who take pride in a rich and proper use of Sranan. It is such speakers that $I$ have tried to single out for judgements and data. But it remains a fact that one is confronted with varying and often conflicting reports and data of actual use. And even when it begins to become clear that certain variants belong together in a grammatically definable variety of the language, it often remains far from clear what the sociolinguistic connotations are of the varieties that are discerned. Obviously, a great deal of sociolinguistic research will have to be carried out before one can make reliable statements about the social, geographical and interactional distributions of the variant forms. This work has not been done yet, and consequently, everything that is said or suggested in this paper about variant forms and their sociolinguistic correlates must necessarily be provisional, until systematic data become available.

On balance, it seemed best to distinguish two main varieties of the 
language. One variety made the impression of being the representative one. It was found with the majority of the informants. We shall speak of this as 'System A'. The other was represented by a minority of the speakers consulted. Here the impression was that one had to do with a relatively recent development, possibly associated with urban life and with males more than with females. But, as has been said, the distinction as well as the suggested connotations can only be provisional as long as data from systematic sociolinguistic fieldwork are lacking. ${ }^{3}$

One minor problem was sometimes presented by the fact that ordinary spoken Sranan shows a great deal of grammatically and phonologically regular contraction which is, however, not always recognised as such by the speakers. In particular, the normal form for uncontracted ben e is bee, with lengthened vowel, a double intonation peak, and loss of the nasal. Speakers often confused this with single ben. But once the difference had been explained, they unfailingly distinguished the two forms consistently. Voorhoeve $(1957$; 1962) aimed at a faithful broad phonetic rendering of what his informants actually said, without applying a morphological analysis. This practice will not be followed here: all the sentences and isolated forms will be spelt in full, without the contractions of the spoken language. There is no danger of misrepresentation here, since the analysis required is unproblematic. The formal spelling has the advantage of displaying grammatical structure more clearly. ${ }^{4}$

\section{System A}

\subsection{Data}

We must begin by making a fundamental distinction between two classes of verbs in Sranan, those which I shall call A-verbs ('auxiliary verbs' in a broad sense), and those which will be called E-verbs (since their most striking feature is the fact that they require the particle $e$ in some cases). The class of A-verbs is very limited, and can be given by simple enumeration. But the class of E-verbs is open-ended: all regular verbs are E-verbs, and all verbs resulting from derivational processes or from lexical innovation are likewise E-verbs. The list of A-verbs is as follows (disregarding minor variations):

$\begin{array}{llllll}a b i & \text { 'have' } & \text { wani 'want' } & \text { nen 'be called' } \\ \text { sabi } & \text { 'know' } & \text { kan 'can, may' } & \text { musu 'must' } \\ \text { gersi } & \text { 'resemble' } & \text { man 'can, may' } & \text { sori } & \text { 'look as if' } \\ \text { lostu } & \text { 'feel like, enjoy' } & s a & \text { 'will' } & \text { lobi } & \text { 'like, love' } \\ \text { the verb BE } & & k b a^{5} & \text { 'finish' } & & \end{array}$

the tense particles $e$, ben, and $o$, if taken as verbs 
Roughly speaking (we will be much more precise below), A-verbs do not get the particle $e$ in the present tense. Yet, we often find A-verbs with $e$ in the present tense. This is very confusing for the observer at the beginning, but closer inspection shows that in all those cases there is a form of LEXICAL DERIVATION at work, whereby A-verbs turn into Everbs, with some change of meaning. The derivational categories that I have been able to discern are the following.

a. The derivation INCHOATIVE, whereby the verb takes on the extra meaning element 'beginning to':
(1) a. safrisafri mi e sabi den pasi $\mathrm{kba}$ slowly I am beginning to know the roads already
b. a e sori bun
it is beginning to look good
c. a e nati it is beginning to be/getting wet

Notice that in (1c) the adjective nati ('wet') has been made into an E-verb meaning 'getting wet'.

b. The derivation CAUSATIVE, which is limited to adjectives and turns them into causative E-verbs:
a. alen e nati yu rain makes wet you
b. yu e weri mi

So we see that adjectives like nati or weri ('tired') can be turned into Everbs in two different ways, according to INCHOATIVE ('getting wet/tired') or according to CAUSATIVE ('make wet/tired'). Clearly, when there is a direct object, the causative meaning is the only one possible.

c. The derivation ITERATIVE-DURATIVE, which adds the meaning element 'frequently' or 'all the time', or 'on each occasion':

(3) a. pe Srananman e de, yu abi prisiri where Surinam people ever are you have fun

(Voorhoeve, 1957: 378)

b. ala dey en mma e kan gi en nyan, every day his mother can give him food ma toku a no e lespeki en ${ }^{6}$ but yet he not respects her

c. mi e siki

I am ill

In (3c) we see a third derivational possibility for adjectives: siki ('ill') has 
been made into a durative verb meaning something like 'spending one's time in illness'. The translation 'I am ill' does not express the durative character of e siki in (3c), but it is the closest natural translation available. This case shows particularly clearly how delicate the distinction can be between a derivational source and a derivational result: mi e siki contains the derived durative verb siki, but mi siki contains the A-verb $\mathrm{BE}$, represented here by a $\theta$-morpheme, and the adjective siki.

(d) The derivation INTENSIVE, intensifying the meaning of the verb:
a. yu no e sabi
a wet so bun
you not really know the law so well

This derivation is the least clearly defined and the most problematic one among them. It does not seem to be entirely productive, but limited to special lexical cases. The resulting meanings do not seem to be entirely predictable. Thus, according to firm assurances by two (main) informants, the sentence:

(4) b. yu no e sabi a wet

(i.e. sentence (4a) but without the adverbial phrase so bun) means 'you are not in a position to know the law'. I have not been able to make out precisely how this works. It is possible that we are dealing with idiosyncrasies of the verb sabi, but further and more specific research will have to answer this question.

These derivational processes, however, are not the topic of this study. They must be mentioned to avoid the criticism of oversimplification. But from now on we will disregard them, and simply maintain the distinction between A-verbs and E-verbs, knowing that some E-verbs are derivations from A-verbs or from adjectives.

One further remark is in order: there is no verbal morphology in Sranan. The verb-form is the same for all persons, moods or tenses. Even the passive voice (which is, however, very limited in Sranan) shows the same verb-forms as the active voice. In our examples below, an arbitrary choice will be made from available (pronominal) subjects, usually mi ('I') or $a$ ('he/she/it').

We can now give the relevant paradigm examples. Let us start with Everbs in finite verb position:
a. mi e nyan
I pres eat
'I eat; I am eating'
b. mi nyan
I eat
'I have eaten; I ate' 


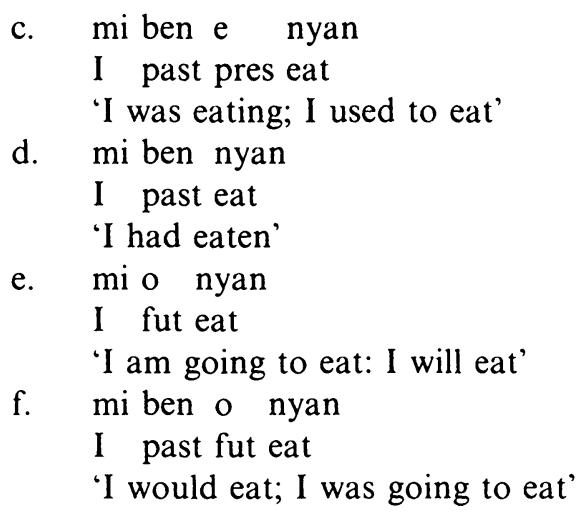

The past tense expressed by $(5 b)$ is ambiguous between a resultative perfect and a simple past indicating a fact that took place at some time in the past. Thus we have mi nyan kba ('I have eaten already'; see Note 5), but also dan mi fadon ('then I fell'), or dan mi broko mi futu ('then I broke my leg') in the simple past. The past tense in (5c) is durative or iterative: 'I used to eat' or 'I was eating'.

One special observation must be made regarding the simple past tense, i.e. the form corresponding to the meaning 'I ate'. In older forms of the language one often finds mi ben nyan, next to the frequent mi nyan. The form mi ben nyan is still not extinct or obsolete, though apparently less frequent than it used to be. Some of my informants representing System A did not accept mi ben nyan at all in this meaning, but others did, though they also accepted mi nyan. None of the System B speakers had mi ben nyan in the meaning of 'I ate'. It is not immediately obvious what one should make of this situation. The possibility that both past tenses cooccur within the same system, but with some semantic difference, should not be excluded. But I have not been able to detect any such difference. Perhaps more realistic is the view that we have here a system in change, probably with even the categories changing. Further detailed study is called for here.

The rule system presented below is based on the simple past without ben. Note, however, that a very slight change in the rule system suffices to get the simple past with ben: all that is needed is the inversion of the order of the spelling rules $S-1$ and $S-2$, in System A (not in System B, since the simple past with ben does not seem to occur in System B).

A little side remark may be permitted here. I found that not only the difference, just discussed, between the two past tenses, but also the differences between System A and System B, can be accounted for by extremely simple modifications in the rule system. It strikes me as, 
somehow, intriguing that all the varieties found in the speech and the judgements of my various sources are accountable for in such a simple way, leaving the rule system intact as one coherent whole. Although I am sure that the rule system in question is defective in many ways, I still wonder about this unity in variation. Is there an implication for the description of linguistic variability in general? Have we hit upon a possible measure for the realistic value of the description? I dare not suggest answers to these questions.

When we look at the forms expressing references to past events or situations, i.e. ( $5 b, c$ and $d$ ), it is clear that they look semantically irregular. It is not so bad for the present, as in (5a), or the simple future (5e), or the past future (5f), where $o$ can be taken to indicate the future, and ben the past. Further semantic irregularities will show up below, in the paradigm of the A-verbs, infinitives, and of the future auxiliary verb sa. Let us have a look at the A-verbs in finite verb position:

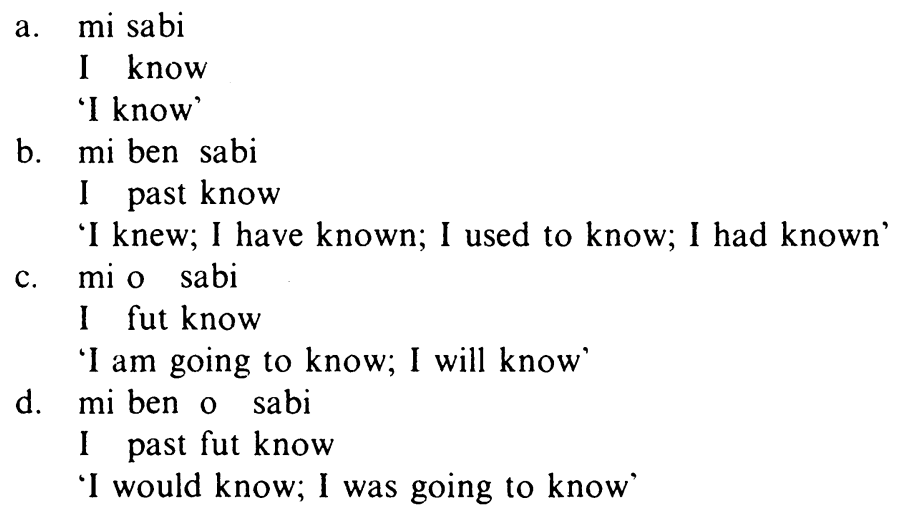

Here we notice that the particle $e$ does not show up at all. Furthermore, the three past tenses of $(5 b),(5 c)$ and $(5 d)$, respectively, have been amalgamated into the one (6b), which is, accordingly, multiply ambiguous.

If all verbs had been A-verbs, the semantic description would have been simple: ben would have been taken as an indiscriminate marker of 'past', and total absence of particles would indicate the present. But in the E-verb paradigm we see that total absence of particles indicates not the present but the past. This paradigm has, moreover, the particle $e$, whose meaning or function is not altogether clear.

Let us now inspect the paradigm of the infinitives. Some A-verbs can be followed by an infinitive (wani, sabi, kan, man, musu, gersi, lostu, sa, lobi, $k b a$ ), as well as some prepositions ( $f u$ 'for to'), or E-verbs ( $g o$ 'go'). The infinitives can take $e$ and/or ben, but not $o$. The paradigm is as follows: 
(7) a. a kan nyan

he can/may eat

'he can/may eat'

b. a kan e nyan

he may pres eat

'he may be eating'

c. a kan ben nyan

he may past eat

'he may have eaten'

d. a kan ben e nyan

he may past pres eat

'he may have been eating'

(Of course, kan and any other A-verb that takes an infinitive, can itself occur in different tenses, in which case it follows the paradigm of (6).)

For many speakers, musu (must) has a special feature: its infinitive never takes ben, even though the meaning would make us expect it. The particle ben, when expected semantically after musu, stands in front of musu:

(8) a. *a musu ben nyan

b. *a musu ben e nyan

c. a ben musu nyan

'he must have eaten; he had to eat'

d. a ben musu e nyan

'he must have been eating; he should be eating'

I found this to be the case with enough representative speakers for it to seem justified to include a special transposition rule $(T-2)$ for this verb, in Section 1.3. Note that such transpositions are not unusual. Compare e.g. English he should have run with French il aurait dû courir, German er hätte rennen sollen, or Dutch hij had moeten rennen. We see that there is an element 'past' that has hopped across the finite verb form in English and is attached there to the non-finite form run, whereas in the other languages cited that element has remained in the position before the finite verb, together with a second past, thus giving rise to the morphological past perfect aurait dî, hätte ... sollen, had moeten. Assuming, of course, (a) that English 'past' in non-finite position becomes have (cp. McCawley, 1971), and (b) that double 'past' becomes a morphological past perfect, at least in French, German and Dutch (not to mention English and Sranan).

We notice that $e$, at least with $\mathrm{E}$-verbs, typically occurs in forms with a durative or iterative meaning: (5c), (7b), (7d). For the present tense (5a) we can say that it must, of necessity, be durative, since it is simply impossible to indicate a point-event in the present. A point-event is by definition a 
sudden transition between one state and another. It does not itself cover any length of time, no matter how small. It marks the point of transition between not yet having reached a state and having reached it, such as winning a race, reaching the top, or hitting the ground. Such events can only be referred to in the past or the future (or in a timeless way). We can say, e.g. he hit the ground, thereby referring to the extensionless moment of impact in some defined past time, but we cannot do the same for the present time, the time of speaking, probably because the process of speaking itself takes time. All we can do in the present is say that the point-event is included in the time of speaking: he is now hitting the ground. Thus we are justified in saying that the occurrence of $e$ in (5a) is another case of $e$ with a durative meaning.

This phenomenon has led earlier researchers, including Voorhoeve (1957), to assume that $e$ is a marker of durative aspect and not a tense particle. This assumption is reinforced by the consideration that $e$ is derived from the older $d e$, one of the forms of the verb BE. Just as there is some justification for taking the English verb be in the English progressive form as a durative aspect marker, one may feel justified in considering Sranan $e$ a durative aspect marker. In the analysis presented below a different position will be taken, however. Although in older stages of the language $e$ (or rather $d e$ ) may well have functioned in a way similar to English $b e$ in the progressive form, it does seem that nowadays $e$ is a tense marker for the present or for temporal simultaneity. But there are rules for the deletion of $e$ (i.e. reduction to 0 ). These rules are subject to certain conditions, one of them being the durative or non-durative character of the E-verb: when the E-verb is durative, $e$ is not deleted. Thus, in a secondary way, $e$ still is a durative aspect marker, since its presence shows that the main E-verb is durative. In System B, which is more recent than System A, durativity no longer plays a part in the deletion of $e$, so that $e$ has lost its old function of marking durative aspect altogether. We shall see that all that is needed to achieve this is a very minor modification in the rules.

Having given the three main paradigms, for finite E-verbs, finite Averbs, and infinitive E-verbs (infinitive $\mathrm{A}$-verbs are like infinitive $\mathrm{E}$-verbs, except that they never take the particle $e$ ), we must consider the auxiliary verb $s a$ and the verb BE separately, both being considerably more complex than the other verbs.

$S a$ is analysed here (unlike Voorhoeve's analysis, where $s a$ is a verbal particle) as a modal auxiliary. As with so many modal auxiliaries in all kinds of languages, the paradigm is defective: $s a$ does not occur as an infinitive (9d); nor does it take the future particle $o(9 \mathrm{e})$. But it does allow for ben preceding and/or following it $(9 a, b$ and $c)$. It has the further 
peculiarity that, when in the past or perfect (i.e. preceded by ben), and followed by a past infinitive (i.e. also with ben), the second ben is deleted; hence the ambiguity of $(9 \mathrm{~b})$. Only rarely do we find ben sa ben as a grammatically correct sequence: (9c). In these cases ben sa is the past of the modal, and expresses the speaker's disbelief; the second ben represents the past perfect. Since in the rules below the past perfect is derived from ben ben in underlying form, the simplest solution is to insert a rule deleting one occurrence of ben after $s a$ when $s a$ itself is preceded by ben. This rule is given below as $T-3$.

(9) a. a sa ben nyan

'he will have eaten'

b. a ben sa nyan

'he would eat; he would have eaten'

c. a taki dati mi ben sa ben du en

'he said that I <subjunctive> had done it'

d. *mi abi fu sa gwe

'I have to 〈future $\rangle$ go away'

e. *mi o sa nyan

'I will shall eat'

Semantically, $s a$ has a variety of functions. It indicates future or temporal posteriority relative to a defined moment of time. In this respect it resembles $o$, but the two are not identical. I have found it difficult to formulate the relevant semantic generalisations covering the correct temporal usage of $s a$ and $o$. As a tentative approximation it seems that $s a$ is the proper form for neutral predictions, but also for future events or situations resulting from somebody's (the speaker's) insistence, order, wish or promise. $O$, on the other hand, indicates a future event or situation resulting from some pre-established plan or from natural causes already present at the time of speaking.

But apart from its temporal meaning, sa has modal functions, and these are more salient than the temporal meaning. $S a$ indicates the speaker's wish or order: yu sa go ('you shall go'), or the speaker's hypothesis: a sa ben dringi doti watra ('he will/must have drunk dirty water'). It may also express the speaker's disbelief or doubt as to the truth of what is said in the following infinitive. In this latter meaning it tends to occur in the past tense, ben $s a$, and does what the subjunctive does in so many other languages. An example is (9c) above, which does not mean simply 'he said that I had done it', but adds, by means of ben sa, the speaker's implicit denial of the truth of the subordinate clause. Thus $s a$ can be used, in the present, to refer to the future but is predominantly modal. $O$, on the other hand, is predominantly temporal but can, with ben, 
be used modally: unu no ben o kari en so ('we would not call it that').

Voorhoeve (1957: 383; 1962: 39) distinguishes between 'realis' and 'irrealis' forms, according to whether or not the state or event referred to is real (i.e. entailed by the truth of the clause in question). Thus, ben, ben-e, $\theta$ and $e$ are given as 'realis' forms, but ben-sa, ben-sa-e, sa and sa-e as 'irrealis' forms (he does not give sa-ben or ben-sa-ben). In the present analysis, as he has been said, $s a$ is a modal auxiliary belonging to the A-class, and the 'irrealis' character of the forms with $s a$, pointed out by Voorhoeve, is here taken to be due to the modality expressed by the auxiliary verb $s a$.

$S a$ occurs regularly in the main clause of past counterfactuals, as in (10a), where the past perfect, with ben, is used in the subordinate clause, just as in English. In present counterfactuals, as in (10b), ben $o$ seems to be preferred in both clauses:

(10) a. efu a ben wroko moro tranga, a ben sa kisi moro moni 'if he had worked harder, he would have earned more money'

b. efu a man ben o meki bari now, a fowru ben o frey gwe 'if the man were shouting now, the bird would fly away'

We have not exhausted all the semantic possibilities of the auxiliary sa. Voorhoeve mentions other uses as well, but I have not checked these uses and will not comment on them.

Finally, we must consider the complexities of the verb BE in Sranan. The verb $\mathrm{BE}$ occurs in four guises: $d e, n a, a$, and $\theta$. Here are some examples:
a. a tru
b. a musu (de) tru
c. a ben tru

d. a liba bradi

e. o bradi a liba de?

f. o bradi a liba bradi? $\}$

g. a no bigi so

h. a no de so bigi $\}$

i. o lati a de?

j. mi na datra

k. en na datra

1. na datra

m. mi ben de datra

n. yu musu de datra 'it is true'

'it must be true'

'it was/has been/used to be/had been true'

'the river is wide'

'how wide is the river?'

'it is not that big'

'what time is it?' lit: 'how late is it?'

'I am a doctor'

'he/she is a doctor'

'it's a doctor'

'I was/have been/used to be/had been a doctor'

'you must be a doctor' 

o. a (de) drape
'he/she/it is there'
p. a de inisey
'he/she/it is inside'
q. a musu (de) drape
'he/she/it must be there'
r. na gi en
'it is for him/her/it'
s. a no gi en
t. mi a no datra ${ }^{7}$
'it is not for him/her/it'
'I am not a doctor'
u. en a no datra
v. a no datra
'he/she is not a doctor'
'it is not a doctor'
w. a wani de datra
'he/she wants to be a doctor'
x. a no ben de datra
'he/she was not/has not been/had not been a doctor'
y. a de fo yuru/unu de fo 'it is four o'clock/we are four yuru o'clock'
z. mi de na ini Sranan
'I am in Surinam' Kondre

There is, furthermore, the extremely frequent and highly idiomatic use of $n a$ in cleft constructions. Examples are:
a. na dri yuru
unu de
it is three hours (that) we are 'it is THREE o'clock'
b. na Ronald fufuru en
it is Ronald (that) has stolen it 'RONALD has stolen it'
c. na Ronald en ppa yagi gwe it is Ronald (that) his father has chased away 'his father has chased RONALD'
d. na fufuru a fufuru en it is steal (that) he has stolen it 'he has STOLEN it'
e. na bigi yu futu bigi it is big (that) your feet are big 'your feet are BIG'

The analysis of this construction is 'it is that ...', where the element corresponding to that (taki) undergoes deletion (as in informal English: 'it's you will be responsible'). This idiomatic $n a$ in cleft constructions has the special property of being insensitive to tense, or in some not altogether clear sense, of being tenseless, as appears from the sample text in Section 4, where we have several instances of $n a$ in what one would expect to be past tenses.

This may well look fairly chaotic. But we shall see that it is not too 
difficult to state the regularities. A few things immediately strike the eye. Thus we see that the subject pronoun $a$, which everywhere else in the language means 'he/she/it', is replaced by en for the meanings 'he/she' and by $\theta$ for the meaning 'it' when followed by $n a$ ('is') or by $a$ no ('is not'). ${ }^{8}$ Then we notice that in infinitive position the form de is always allowed, though not always obligatory: sometimes it may be replaced by 0 . The form $n a$ only occurs in the present tense (or tenselessly) and in finite verb position, and it never occurs with no. Instead of the expected no na we always get $a$ no. This, in fact, is the only case where $a$ stands for the verb $\mathrm{BE}$; see $(11 \mathrm{~s}-\mathrm{v})$. Finally, we remark that $\theta$ can stand for BE, in particular when BE is followed by an adjective, as in (11a-d), (11f), (11g). But when for some reason or other the adjective does not come immediately after the verb $\mathrm{BE}$, we find the form de for $\mathrm{BE}$, as in (11e) and (11h). We shall see below that a few not too complicated rules will get all these facts straight. But it will be necessary to assume so-called 'underlying forms', postulated for the sake of simplicity of description, and rules converting these into the correct surface forms. The underlying forms will have to be semantically regular. The semantic irregularities of the surface forms will then be explained, in a certain sense, by the rules converting the underlying forms into the surface forms. The simpler these rules, the better the explanation.

One last feature must be observed. It has been said earlier that Sranan speakers regularly 'fall back' on Dutch to fill in missing lexical items, often even in cases where it is not necessary to do so. Sranan purists justifiably object to unnecessary borrowing from Dutch (or any other language), but it is nevertheless a fact that it happens very frequently. ${ }^{9}$ What is relevant here is that when an adjective is an unadapted borrowing from Dutch, the verb $\mathrm{BE}$ is usually represented by de:

(13) a. mi de enthousiast

'I am enthusiastic'

b. a de overtuigd

'he is convinced'

This is a further indication that it is wise to operate with postulated underlying forms (in this case the verb $\mathrm{BE}$ ) manifesting themselves in different guises, often as $\theta$, in the surface forms, according to certain regular principles called 'rules'. The following section will be devoted to a specification of the underlying forms.

\subsection{Underlying forms}

The main feature of the underlying forms postulated for the description of Sranan tenses and aspects is the so-called 'double tense analysis'. This 
involves the assumption of two tenses, $\mathrm{t} 1$ and $\mathrm{t} 2$, for each occurrence of a verbal form in either finite or infinitive position. Such an analysis is not a novelty invented, more or less ad hoc, for the description of Sranan. On the contrary, it originates with Reichenbach (1947), where a distinction is made between the point of speech (S), the point of reference (R), and the point of the event (E). In these terms Reichenbach tries to provide an adequate semantic description of the tenses of English. Grammatically, this corresponds to the assumption of two morphemes, one indicating the relation between $S$ and $R$, and the other the relation between $R$ and $E$. Mufwene (1980) uses, in principle, the same analysis for Guyanese and Jamaican Creole. Rigter (1980a and b) applies a double tense analysis to a full grammatical description of the tenses of English. In general, it seems that this analysis applies to all languages (there is no counterevidence available at present, though it must be said that, so far, the double tense analysis has not been tried out on many languages). What many languages do have is additional semantic and/or grammatical parameters contributing to the tense/aspect system.

Although the analysis presented here is based on the assumption of exactly Two underlying tenses for each verb form, it is, in principle, not incompatible with the theory that there may be cases with more than two tenses (as is implicitly assumed in McCawley, 1971). I would, in particular, not rule out $a$ priori the possibility of, say, underlying ben-ben-e, standing for something corresponding to 'had been ___ing', as in alaten wan sari sani ben e pasa (Section 4, line 34). Although this means 'always something sad happened', the meaning 'had been happening', derivable, conceivably, from ben-ben-e, also fits the context. But Sranan does not seem to have a past perfect with durative $e$. If it appears that a multiple tense analysis is to be preferred to a double tense analysis, the consequences for the analysis given here will be slight: it will be a simple matter to adapt the analysis accordingly. Meanwhile, I shall abide by the double tense analysis, with $\mathrm{t} 1$ for the first, and $\mathrm{t} 2$ for the second occurrence of 'tense'.

In Sranan, $\mathrm{t} l$ can be represented by $e$ and by ben, but $\mathrm{t} 2$ can be $e$ or ben or 0 . I will, in general, label these as 'particle', although it is equally possible to label them as 'verb', in accordance with McCawley, 1971. In Section 3 the rules are reformulated (with a certain gain in simplicity) with $b e n, e$ and $o$ labelled as 'verb' (V). Historically, they are all verbal forms: $e$ from de meaning 'be', ben from English been, $o$ from $g o$. In modern Sranan they can be seen as fossilized verbs or as isolated particles. Some informants spontaneously referred to them as 'verbs', whereas others were surprised that such a label could at all be applied.

The semantic description of $t 1$ and $t 2$ is as follows. The first tense, $t 1$, is DEICTIC ${ }^{10}$ in that it places its scope, i.e. $t 2+$ the verb, at some moment or in 
some duration defined by the context of utterance. Thus, in finite verb position, $e$ places what is described by $\mathrm{t} 2+$ the main verb at the time of speaking. In infinitive position it puts its scope at the time given by the finite verb commanding it. Ben in the position of $t 1$ always refers to some specified time in the past: 'at that time/moment'. The time or moment in question is defined either by previous discourse, as in the second sentence of:

(14) a. Esde mi ben e koyri. Dan mi fadon. 'Yesterday I was walking. Then I fell.'

or by a clause or an adverb in the sentence itself, as in the main clause of:

a. Di yu doro, a dagu ben breti.

'When you arrived, the dog was happy.'

We would analyse (14a) in terms of the following underlying forms:

(14) b. esde mi ben e koyri - dan mi ben e fadon yesterday I past pres walk then I past pres fall

and (15a) as:

(15) b. di yu ben e doro, a dagu ben e BE breti when you past pres arrive, the dog past pres be glad

In (14b), the past time referred to by the first ben is defined by esde ('yesterday'). But in the second sentence the reference of ben is given by what has been said in the first sentence. (15a) presupposes that previous context has defined the moment of the addressee's arrival. The subordinate clause refers to that moment: 'at the moment that (=when) you arrived'. The main clause does the same: 'at that moment the dog was happy'. We will, of course formulate the conditions under which underlying ben-e stays ben-e, or is deleted, or becomes just ben.

The second tense, $t 2$, is RELATIONAL: it indicates that its scope, i.e. just the verb, is to be taken as taking place either simultaneously with the time defined by $\mathrm{tl}(e)$, or prior to $\mathrm{tl}$ (ben) or later than $\mathrm{tl}(o)$. (As we saw in the preceding section, $o$ can only occur as $t 2$ with finite verbs, not with infinitives.) The most convenient paraphrase for ben as $\mathrm{t} 2$ is 'at some time previous to $\mathrm{tl}$ ', and for $o$ 'at some time after $\mathrm{tl}$ '. Thus, an underlying form such as:

mi e ben nyan

must be read as 'now, at some time previous to now, I ate', or less horridly as 'it is now the case that at some time in the past I ate', which corresponds to 'I have eaten'. And the underlying form: 
(17) mi ben ben nyan

is to be interpreted as 'at that time in the past it was the case that previous to that time I ate', which is 'I had eaten'.

For the grammatical specification of the underlying forms the following simple rewrite rules generating underlying tree structures will suffice:
a. $\mathrm{S} \rightarrow \mathrm{NP}-(\mathrm{no})-\mathrm{VP}$
b. $\mathrm{VP} \rightarrow \mathrm{V}_{1}-(\mathrm{R})$
c. $\mathrm{V}_{1} \rightarrow \mathrm{t} 1-\mathrm{V}_{2}$
d. $\quad V_{2} \rightarrow t 2-V$
e. $\quad \mathrm{V} \rightarrow$ Main Verb

The symbol ' $R$ ' in (18b) stands for 'remainder'. It may consist of a number of categories: NP, PP, VP, Adjective or Adverb. A full specification of this part of the grammar of underlying tree structures is not necessary for this study. The symbol 'Main Verb' in (18e) stands for any E-verb or A-verb in the lexicon. The symbol $\mathrm{t} l \mathrm{can}$ be expanded as either $e$ or ben. The symbol t 2 as $e$, ben, or $o$ (but $o$ is not allowed in infinitives or before $s a$ ). V-clusters generated by these rules are thus of the following general form:

(19)

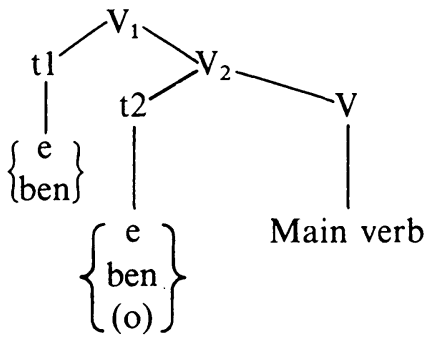

On the basis of the rules given in (18) and the associated lexicon we may form the following underlying structure:

(20)

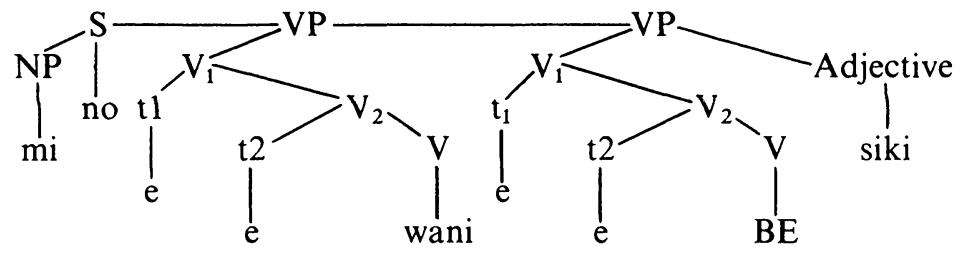

which will have to correspond to either of the following:
a. mi no wani siki
b. mi no wani de siki $\}$ 'I don't want to be ill'.

Thus, the following particle-verb combinations are possible: 


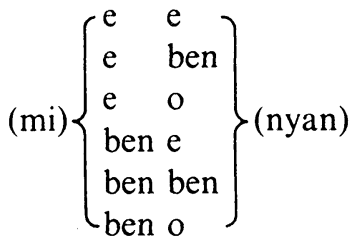

except that the combinations with $o$ are not allowed before $s a$, nor before infinitives.

One further detail must be specified. As we have seen, main verbs sometimes refer to a point-event, but sometimes also to a stretch of time or a duration. This semantic property must be marked in the underlying trees, since it is a factor in the application of the rules converting the underlying structures to the correct surface structures. We have seen above that the present tense cannot but be a durative tense. But the nonpresent tenses can be either durative or they can present what is described by the verb as an event, several of which may have occurred in some particular order. In English, roughly speaking, the difference is expressed by the simple past (I fell) as against the past progressive (I was falling). The A-verbs share the property that, in non-present tenses, they cannot occur referring to a point-event: they are, so to speak, durative by nature. But most E-verbs allow for event readings as well as for durative readings in non-present tenses.

We will indicate the durative or non-durative character of the main verb by means of a feature, $[+d]$ or $[-d]$, attached to the main verb. We will assign the feature $[-d]$ automatically to all A-verbs. (They don't need to be marked for 'durative', because they already are durative by nature.) We will also assign the feature $[+d]$ automatically to all E-verbs in finite verb position when they are preceded by $e-e$. But for the remaining cases there is no automatic syntactic way of assigning the feature $[+d]$ or $[-d]$ to main E-verbs: there the feature will depend on the semantics of the sentence. ${ }^{11}$

Two more feature assignments will have to be carried out, both automatic. First, we assign the feature $[+\mathrm{e}]$ to all E-verbs in finite verb position, and the feature [ $-\mathrm{e}]$ to all other verbs (i.e. to all A-verbs, and to all infinitive E-verbs). Finally, we assign the feature $[+\mathrm{f}]$ to $\mathrm{BE}$ when it is finite, and $[-f]$ when it is infinitive. Note that the feature $[+f]$ or $[-f]$ is defined solely for the verb $\mathrm{BE}$. The point of these feature-assignments is that the rules needed for the conversion to surface structures are sensitive to these features, as we will see. ${ }^{12}$

The VP of (20) will thus be adorned (automatically) with the following feature complexes: 
(23)

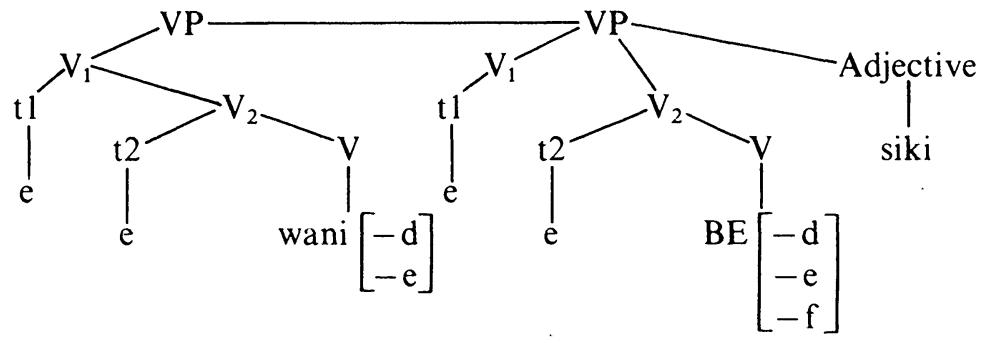

Another example is the following:

(24) a.

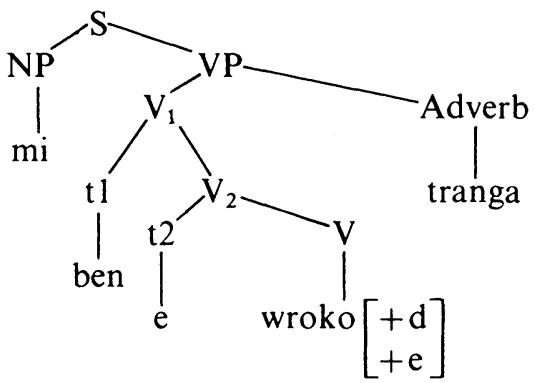

b.

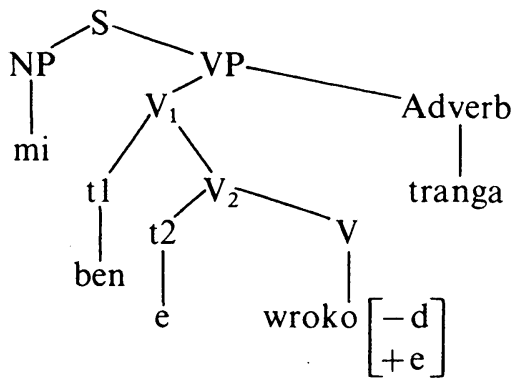

The only difference between (24a) and (24b) is that the former has the feature $[+d]$ for its main verb, whereas the latter has the feature $[-d]$. (24a) will have to correspond to (25a), and (24b) to $25 \mathrm{~b}$ ):

(25) a. mi ben e wroko tranga

'I was working hard'

b. mi wroko tranga

'I worked hard'

\subsection{Rules}

It is now time to consider the rules. The rules needed are of two kinds. First we have a few TRANSFORMATIONAL RULES (T-rules). The first Trule needed really is two rules: it is the rule needed to get the proper fronting of question words or question phrases, and there are two ways of doing so, as was exemplified in (1le) and (11f). In Sranan, question words are fronted, leaving behind either an empty site or a copy of the question word or phrase just fronted. There is no inversion of subject and finite verb form (as in German or Dutch), or other modification in the sentence structure. Since question formation is not central to the description of 
verbal tenses and aspects, I shall give the rule schematically, without any specification of details, such as the precise conditions under which a copy can or cannot be left behind. I shall simply assume that question words or expressions are fitted out with a feature $[+\mathrm{Q}]$, triggering the T-rule(s) ${ }^{13}$ In bare outline, question formation goes as follows:

\section{$T-1$ Q-Fronting: $\mathrm{X}-[+\mathrm{Q}]-\mathrm{Y} \Rightarrow[+\mathrm{Q}]-\mathrm{X}-$ (copy) $-\mathrm{Y}$}

A second T-rule is needed for the transposition of ben across musu, as exemplified in (8) above. We thus assume the following rule, which is idiosyncratic, it seems, for musu:

\section{T-2 musu-ben-Hopping: $\mathrm{X}-$ musu $-(e)-$ ben $-\mathrm{Y} \Rightarrow \mathrm{X}-$ ben - musu $-(e)-\mathrm{Y}$}

This rule does not cover cases where we have underlying ben - ben following musu. I have been unable to find any evidence that would pertain unequivocally to such cases. The dominant reaction was that a form like ben - musu - ben was not acceptable, but it was hard to elicit responses to forms with the meaning 'it is (now) necessary that he had eaten'. It is probably safest to assume that, in those cases too, the resulting form should be ben - musu. If that is so we must either complicate the formulation of $T-2$ in such a way that ben - ben after musu becomes single ben before musu. Or, alternatively, we order the hopping rule AFTER the spelling rules $S-1-S-5$. The rule $S-6$ will then come last of all. This, however, has the disadvantage of having a non-spelling rule in the midst of a series of spelling rules. I shall not try to solve the dilemma: further and more mature research will no doubt show the right way out.

A third rule will have to account for the deletion of ben after sa preceded by ben:

$T-3$ sa-ben-Reduction: $\mathrm{X}-b e n-(e)-s a-(e)-b e n-\mathrm{Y} \Rightarrow \mathrm{X}-b e n-(e)-s a-$ (e) $-\mathrm{Y}$

This rule is not allowed to apply twice. In case $s a$ is followed by ben - ben, as in (9c), the resulting string is ben - sa-ben.

The three $\mathrm{T}$-rules given above bring about the structural adjustments required in the underlying trees for them to be input to the SPELLING RULES (S-rules). These are the rules that do the important work. They should be considered morphophonemic rules: rules that assign a phonological form to certain given morphemes under certain specific conditions. Apart from the obvious complexities of the copula-verb BE, we can keep the spelling rules extremely simple, provided we read them according to the following specification.

They are ordered, and must be allowed to apply repeatedly, till all the work is done. Most S-rules are context-sensitive, which means that their 
(optional or obligatory) application is limited to certain environments. (The S-rules given here are all obligatory.) Environment conditions are indicated (as is the custom) by an oblique stroke; an extended horizontal line indicates the position of the element in question. When an environment condition (or symbol in it) is surrounded by simple brackets, the condition (or the symbol) is optional. Rule $S-2$ contains a negative environment condition, indicated by a horizontal line above the environment specification. Rule $S$ - 2 is thus to be read as follows: 'rewrite ben as $\theta$, whenever it is followed by a $\mathrm{V}_{[+\mathrm{e}]}$, except when preceded by ben'. The succession ben - ben thus remains untouched in all cases, until rule $S$ - 6 replaces this succession by one single occurrence of ben.

The symbol ' $\theta$ ' ('zero') as a rewriting means that the element on the left of the arrow is deleted. We use it as an auxiliary symbol in the grammar. A very late rule will automatically wipe out all occurrences of $\theta$. In applying the rules we stipulate that the symbol ' $\theta$ ' plays no role in environment

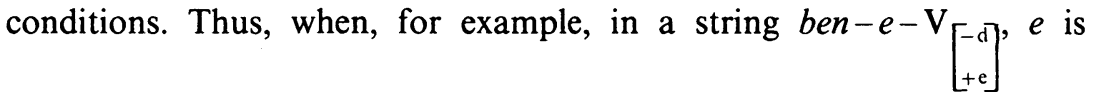

rewritten as $\theta \theta$ (i.e. is deleted) in virtue of $S$ - 1 , ben will be deleted likewise, this time by $S-2$, even though $\theta$ stands between it and the verb.

Here are the rules:

$S-1 \quad e \Rightarrow\left\{\begin{array}{l}e / \ldots \\ \theta\end{array} \mathrm{V}_{1+\mathrm{d}]}\right\}$

$S-2$ ben $\Rightarrow \theta / \overline{b e n} \ldots \mathrm{V}_{1+\mathrm{e}]}$

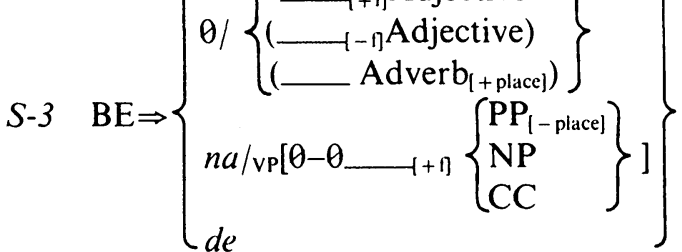

$S-4 \quad a \Rightarrow\left\{\begin{array}{l}\theta / \longrightarrow+\text { neuter }(\text { no })-n a \\ \text { en } / \longrightarrow \text {-neuter })(n o)-n a\end{array}\right\}$

$S-5$ no $-n a \Rightarrow a-n o$

$S-6$ ben $-b e n \Rightarrow b e n$

Note that only $S-1, S-2$, and $S-6$ are directly relevant for tense and aspect, and that nothing other can happen to $e$ or ben than reduction to $\theta$, i.e. deletion.

The features [ \pm place] and $[ \pm$ neuter] have not been defined; the assumption is that a more complete formulation of the grammar will provide adequate definitions. 
The symbol 'CC' in $S$-3 stands for 'clefted constituent': it specifies the form $n a$ for $\mathrm{BE}$ in the cleft construction, exemplified in (12). The preceding environment $\theta-\theta$ can only result from underlying $e-e$, since $\mathrm{BE}$ is an $\mathrm{A}$ verb and therefore $[-\mathrm{d}]$ and $[-\mathrm{e}]$. No specification is given for the underlying form of tenseless $n a$, as it occurs in the'cleft construction. The safest assumption is, perhaps, that it will likewise (idiosyncratically) be $\theta-\theta$.

$S$-5 might look surprising: why on earth should there be a rule turning no na into a no? Again, the simple answer is: we are forced by the facts. But we might also draw attention to the fact that it seems to be natural for a human language to avoid successions of phonologically identical or very similar small functional words (particles or clitics). In Spanish, the succession of clitics le lo is ungrammatical, and comes out as se lo. In Italian, we find that le lo changes into glielo. Perhaps something of this nature is going on in $S-5$, where no na comes out as a no.

A similar observation can be made about $S$-6. It is, in fact, quite common in all kinds of languages, that two or more identical small particle-like words in direct succession are reduced to one or in any case undergo some phonological modification. A clear example is provided by Dutch, where we have the sentence Er waren er twee ('there were two of them'). But in subordinate clauses the rule V-Final operates, shifting the finite verb to the end: ... dat er twee waren ('... that there were two of them'). Here we see that the expected *... dat er er twee waren is very clearly ungrammatical. This is the phenomenon of HAPLOLOGY, which, in some adequate formulation, deserves a place in universal linguistic theory. Think also of the ban on been - been in English. In Italian, the succession of the clitics $s i-s i$ is ungrammatical: we find, instead, $c i-s i$ : ci si sveglia presto in montagna ('one wakes up early in the mountains'), where one would expect $* s i-s i$, with the impersonal and the reflexive $s i$ in direct succession.

$S-5$ and $S-6$ thus appear, in the light of what is known about other languages, less surprising than they look at first sight, although it must be admitted that claims based on 'universal linguistic theory' are more suggestive than substantial. (It is interesting to note, in this connection, that in the oldest extant Sranan text, Herlein, 1718 (not more than a few pages), double ben is attested in ben ben aksi, with the possible meaning of 'had asked'. If the text is not corrupted (see Voorhoeve and Lichtveld, 1975: 281, where one of the two bens is conjectured away), and if the meaning is indeed 'had asked' (and not, for example, 'have been asked', which is also possible in the context), then we have in surface structure a form which is postulated in deep structure, - the surface structure in question being a couple of centuries older than the language described by our rule system.) 
One further remark concerning $S-3$ is in order. I have given the $\theta$ representation of $\mathrm{BE}$ as optional, when $\mathrm{BE}$ is followed by $\mathrm{Adverb}_{[+ \text {place]. }}$. But, besides (11o) we also have (11p), where the 0-representation is ungrammatical, and $d e$ is obligatory. ${ }^{14}$ All I can say here is that this detail of BE will have to be investigated further: $S$-3 as given here is, apparently, still too global: The same holds for the environment specification $\mathbf{P P}_{[- \text {place }]}$ for $n a$ in $S$-3: although (11r) is certainly correct, further research will have to ascertain to what extent the specification $\mathrm{PP}_{[- \text {place] }}$ is adequate.

Given the provisos made, we should now be able to generate all the relevant cases of System A correctly. Let us revert to (23), which is the VP of (20). There, all the occurrences of $e$ are reduced to $\theta$, since none is followed by a $\mathrm{V}_{[+\mathrm{d}]}$. The verb BE may, according to $S-3$, be spelled as $\theta$, since it is followed by an adjective while being in infinitive position. But if this $\theta$-spelling is not used, no other option remains than de. Hence (21a) or (21b).

(24a) is left unchanged and becomes the sentence (25a): $e$ is not reduced to $\theta$, since it is followed by a $V_{[+d]}$, and ben stays since it is not followed by a $\mathrm{V}_{[+\mathrm{e}]}$. But in (24b) both ben and $e$ are deleted: $e$ is deleted since it is not followed by $\mathrm{V}_{[+\mathrm{d}]}$; ben is also deleted, since it is followed by $\mathrm{V}_{[+\mathrm{e}]}$ (the intervening $\theta$ does not count).

Let us quickly go through the paradigm examples:

a. $\mathrm{mi}-\mathrm{e}-\mathrm{e}-$ nyan

b. i. $\mathrm{mi}-\mathrm{e}-$ ben - nyan

ii. $\mathrm{mi}-$ ben $-\mathrm{e}-$ nyan $_{[-\mathrm{d}]}$

c. $\mathrm{mi}-$ ben $-\mathrm{e}-$ nyan $_{[+\mathrm{d}]}$

d. mi - ben - ben - nyan

e. $\mathrm{mi}-\mathrm{e}-\mathrm{o}-$ nyan

f. $\mathrm{mi}-$ ben $-\mathrm{o}-$ nyan

(6) a. $\mathrm{mi}-\mathrm{e}-\mathrm{e}-\mathrm{sabi}$

b. i. $m i-e-b e n-s a b i$

ii. $\mathrm{mi}-$ ben $-\mathrm{e}-\mathrm{sabi}$

iii. $\mathrm{mi}$ - ben - ben - sabi

c. $\mathrm{mi}-\mathrm{e}-\mathrm{o}-\mathrm{sabi}$

d. $\mathrm{mi}-$ ben $-\mathrm{o}-\mathrm{sabi}$
$\Rightarrow$ mi e nyan (S-1 deletes the first $e$ )

$\Rightarrow$ mi nyan (S-1 deletes $e ; \mathrm{S}-2$ deletes ben)

$\Rightarrow$ mi nyan (id.)

$\Rightarrow$ mi ben e nyan

$\Rightarrow$ mi ben nyan (S-6 deletes one ben)

$\Rightarrow$ ni o nyan (S-1 deletes $e$ )

$\Rightarrow$ mi ben o nyan

$\Rightarrow$ mi sabi (S-1 deletes $e$ in both positions)

$\Rightarrow$ mi ben sabi (S-1 deletes $e$ )

$\Rightarrow$ mi ben sabi (S-1 deletes $e$ )

$\Rightarrow$ mi ben sabi ( $\mathrm{S}-6$ reduces ben - ben to ben)

$\Rightarrow$ mi o sabi (S-1 deletes $e$ )

$\Rightarrow$ mi ben o sabi
$\Rightarrow$ a kan nyan

$\Rightarrow$ a kan e nyan 

c. i. a - e - e - kan - e - ben - nyan $\Rightarrow$ a kan ben nyan
ii. $\quad a-e-e-k a n-b e n-e-n y a n_{1-d]} \Rightarrow a$ kan ben nyan
iii. $\quad \mathrm{a}-\mathrm{e}-\mathrm{e}-\mathrm{kan}-\mathrm{ben}-$ ben - nyan $\Rightarrow \mathrm{a}$ kan ben nyan
d. $\left.a-e-e-k a n-b e n-e-n_{y a n}+d\right] \quad \Rightarrow a$ kan ben e nyan
a. i. $\quad a-e-e-s a-b e n-e-n^{n a n} n_{[-d]} \Rightarrow$ a sa ben nyan
ii. $\mathrm{a}-\mathrm{e}-\mathrm{e}-\mathrm{sa}-\mathrm{e}-\mathrm{ben}-$ nyan $_{[-\mathrm{d}]} \Rightarrow \mathrm{a}$ sa ben nyan
b. i. $a-e-b e n-s a-b e n-e-$

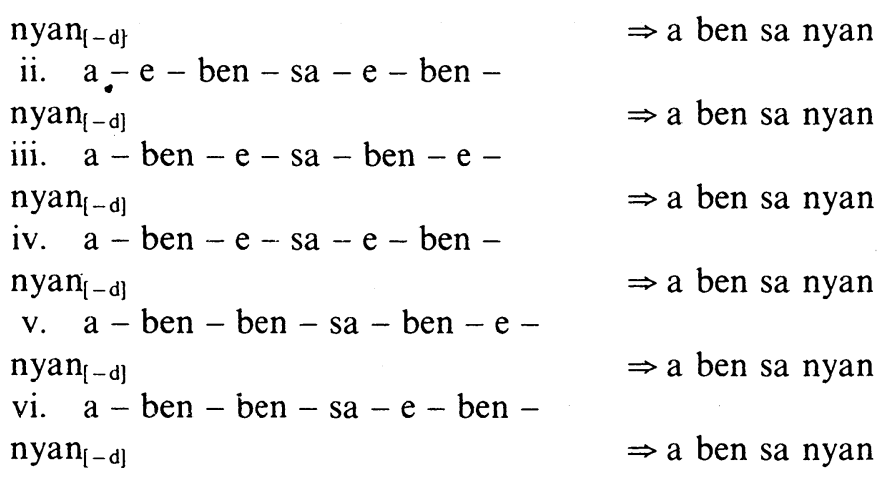

The case of (7c) is interesting. It is threefold ambiguous: 'it is possible that he has eaten', 'it is possible that he ate', and 'it is possible that he had eaten'. Note that exactly the same ambiguity is found in the English 'he may have eaten'. Then (9b) is interesting in that it shows that the sentence a ben sa nyan is six ways ambiguous. It allows for any past tense for $s a$ and any past tense, except ben - ben, for the infinitive nyan. Note that after $T-3$ we have two consecutive bens in (9bv) and (9bvi). But $S-6$ reduces these to one single ben, by virtue of the haplology rule. However, when we have two occurrences of ben after $s a$, the result is ben-sa-ben, since $T-3$ may apply only once. Note furthermore that the infinitive in all these cases is non-durative. When it is durative, the result, in all cases, is a ben sa e nyan.

The various forms of BE, as given in (11) and (12) are generated by $S-3$, $S-4$ and $S-5$. When BE is followed by an adjective and is finite, BE is $\theta$ : (11a, c, d, f, g). But when the adjective has been moved without leaving a copy $(11 \mathrm{e}, \mathrm{i})$, or when the adjective does not follow immediately $(11 \mathrm{~h}), \mathrm{BE}$ is represented by de. When BE is in infinitive position (11b), it is either $\theta$ or de.

BE may likewise be $\theta$ when followed by at least some adverbs of place, such as drape ('there'), as in (110). But with e.g. inisey ('inside'), de is the only possible form, as has already been observed. I have not investigated this detail further.

When BE is present (or 'tenseless'), and is followed by a noun phrase, such as datra, and is also in finite verb position, it takes the form na. $\mathrm{Na}$ is 
likewise the form of present tense (or 'tenseless') and finite BE when certain prepositional phrases follow, such as gi en ('for him/her/it'), or when a clefted constituent follows, as in the cases of (12). In all these cases of $n a$, when the subject is neuter $a$ (i.e. 'it'), it is deleted, by virtue of S-4, as in $(111, r)$ and the sentences of (12). When the subject is non-neuter third person singular pronoun, $S$ - 4 gives the form en, which is normally the non-subject or the emphatic form (see Note 8).

When $\mathrm{BE}$ is represented by $n a$ and is also negative, the sequence no na is replaced by a no, through $S-5$. No na is always ungrammatical. Note, however, that $a$ in $a$ no is not the neuter pronoun subject $a$, but must represent $\mathrm{BE}$. This appears from cases such as $(11 \mathrm{t}, \mathrm{u})$. As a consequence of this, we likewise treat $a$ in $a$ no in sentences like $(11 \mathrm{~s}, \mathrm{v})$ as a form of BE, and not as a subject pronoun: the subject pronoun has been deleted by $S-4$. But in $(11 \mathrm{~g}, \mathrm{~h}, \mathrm{x}) a$ in $a$ no really is the subject pronoun, since there $S-4$ has not applied and BE is represented either by $\theta$ or by $d e$.

\section{System B}

As was pointed out in the Introduction, there is a recognisable sociolectal variant with respect to the representative variety of Sranan which we have been discussing so far. This variant, which we shall call System B, seems to be associated with young, especially male, speakers in urban environments. But the precise correlations will have to be established by detailed sociolinguistic data collecting. The definition of System B offered here is much more tentative than what has been said about System A. Yet, what I have been able to collect in the way of judgements and reactions does point to the existence of such a system. In any case, I shall formulate the differences that I have observed with respect to System $A$, and give the modifications that are required in the rules in order to generate System B correctly. (i.e. in accordance with the presumed facts as they are presented here). We shall see that the modifications are minute.

The main feature characterising System B is the fact that $e$ never occurs with infinitives. There is, therefore, no distinction between durative and non-durative in infinitives, though this distinction is maintained between e.g. mi nyan and mi ben e nyan. Then, the informants in question rejected de for $\mathrm{BE}$ when followed by adjective in infinitive position and present tense. That is, they rejected (1lb) with de.

In order to get these observations straight, we must, simply, change S-1 into:

$$
S-I_{\mathrm{B}} \quad e \Rightarrow\left\{\begin{array}{l}
e / \ldots \\
\theta
\end{array}\left[\begin{array}{c}
+\mathrm{d} \\
+\mathrm{e}
\end{array}\right]\right\}
$$


Then, in $S$-3 BE becomes $\theta$ simply when followed by an adjective.

The new rule $S-l$ is interesting in that it makes the system less aspect oriented and more tense oriented: the occurrence of the particle $e$ is no longer possible with infinitives, and thus loses its function of aspect marker in that position. Recall that the feature $[+e]$ is assigned only to $E-$ verbs in finite position.

\section{Verbal tense particles as underlying verbs}

We have, so far, treated $e$, ben and $o$ as 'particles', which is all right for simple descriptive purposes. But anyone with a somewhat deeper interest in natural language might feel that the category 'particle' really is a very unsatisfactory category in grammar. It may well be necessary to have such a category, but it is a particularly unilluminating one from virtually every point of view. The only way to define particles seems to be a negative way: particles are not inflected, not this, not that. In this respect they are worse even than adverbs. Semantically they are entirely undefinable. On the other hand, we do very often find small, so to speak ossified function words in natural languages, and no better label seems available than 'particle'.

One way out of this, already adopted by many authors for adverbs, is the following. We might propose that 'particle' is a surface structure category, but that it is derived, in the process of conversion from underlying structures to the surface, from other, semantically more palatable categories. At the same time it might well be the case that what can be described in terms of grammatical conversion (transformation) rules in fact reflects a process that took place in the history of the language.

Sranan is particularly attractive from this point of view, since it very easily allows for a reformulation of the rules in such a way that the three particles in question are verbs. ${ }^{15}$ If we treat the particles as A-verbs, they will invariably be assigned the features $[-d]$ and $[-e]$. We now reformulate $S-1$ in System A as:

$S-1_{\mathrm{A}^{\prime}} \quad e \Rightarrow 0 \_\mathrm{V}_{[-\mathrm{d}]}$

and in System B as:

$S-1_{\mathrm{B}^{\prime}} \quad e \Rightarrow \theta /-\left\{\begin{array}{l}\mathrm{V}_{[-\mathrm{d}]} \\ \mathrm{V}_{[-\mathrm{e}]}\end{array}\right\}$

This gives us exactly the same output as before for the two systems. It also makes the formulation of the rules slightly simpler. 
Moreover, as we saw in Section 1.2, the historical evidence is unequivocal: $e$, ben and $o$ were originally verbs. $E$ derives from older de, meaning 'be' (its origin is still unclear). Ben is English been, and $o$ is derived from English, and older Sranan, go. We may repeat the observation made in Section 1.2, that some informants spontaneously referred to these particles as 'verbs', and thought it a matter of course that they should be treated as verbs in the grammar. What seems to have happened is that these old verbs had such uniform and monotonous patterns of distribution that it became a matter of procedural economy to treat them, in the actual processing of production and comprehension, as ad hoc building blocks (called 'particles') rather than as members of the very large and internally diversified category of verbs.

This process of splitting up the enormously large and almost ungraspable category of verbs into smaller categories no longer to be labelled 'verb', is in fact extremely widespread in all kinds of languages. Sranan itself shows some very clear examples, other than the particles already discussed. A clear example is provided by (12c) above: the adverb or adverbial particle gwe ('away') is derived from the verb go away. One should understand gwe in (12c) as a fossilized remnant of what once was a complement clause attached to the object of the main verb: 'so that he go away'.

This particular construction is very typical of Sranan. Vaorhoeve, 1957 spoke of 'the verbal chain'. Nowadays, the term 'serial verbs' is more common. It is a productive construction of infinitives without a preposition or other complementizer, where the understood subject is to be retrieved from a preceding Noun Phrase whether explicitly mentioned or itself only 'understood' but not explicitly mentioned (i.e. 'tacit'). The meaning of the resulting clause is 'so that ...' or 'and thus ...'? serial verbs express a resultative meaning. In System $A$, as is to be expected, the occurrence of $e$ indicates durativity, but in System $\mathrm{B} e$ does not occur at all with serial verbs, these being infinitives. System A allows for sentences such as (26a) and (26b), taken from Voorhoeve (1957), where the serial verbs are $[+\mathrm{d}]$ and thus take $e$ :

a. me ben e du muyti

e leri

a tongo

I was doing trouble so that I was learning the language pikinso

a little

b. dan en nanga Peroti ben drape

e wroko then he and Peroti were there and thus they were working 
(27) a. mi e teki wan sani fu (mi) tyari

I am taking one thing for I carry it so that it

go na abrasey

go to overside

'I am taking something to carry it across' (Voorhoeve, 1957)

b. den man de fu ori yu, grabu yu futu ori the men are for hold you, grab your feet so that they hold a gron

the ground

'the men are there to hold you, grab your feet so that they stick to the ground'

c. mamanten dow ben ari gwe

(Voorhoeve, 1957)

early in the morning dew had pulled so that it go away

$\mathrm{kba}$

already

'early in the morning the dew had dried up already'

d. son safrisafri ben e pusu ede kon sun slowly was pushing head so that it come 'slowly, the sun was pushing its head up'

e. a teki a nefi koti a brede he took the knife with the result that he cut the bread 'he took the knife and cut the bread'16

Here we see these bare infinitives gradually turn into prepositions and adverbs. Go na in (27a) is beginning to mean and to function as 'towards'. In (27c), as in (12c) above, gwe functions as the adverb 'away'. In (27d) $k o n$ is beginning to mean and function as the verbal particle 'up'. ${ }^{17}$

Other examples of verbs turning into other categories are gi ('give'), which also occurs as the preposition 'for', or $k b a$, discussed earlier (Note 5), and derived from Spanish-Portuguese acabar ('finish'). Kba, we remember, occurs either as an A-verb meaning 'finish', or as an adverb meaning 'already'.

\section{A sample text}

Especially since the second world war, literary activities have begun to thrive in the Sranan speaking community. Writers chose either Dutch or Sranan as their language, and sometimes both. The result is that we have some Sranan prose now, and quite a few poems. One of the more notable writers is TREFOSSA (pseudonym of H. F. de Ziel), who died in 1975. In 1944 he wrote a short story 'Moonlit nights' in Dutch. But after the war he 
rewrote the story in Sranan, and had it published in 1959. Voorhoeve and Lichtveld reprinted the Sranan text (1975: 208-214), together with an English translation by Vernie A. February. I take the beginning of the story as a sample text: it is not only excellent Sranan prose, but also contains a wealth of verbal tenses and aspects. The translation is mine. February's English rendering, though very readable, is too free for my purpose.

\section{Owrukuku ben kari}

1 Sonte mun no ben sa skèyn so sari a neti dati, efu wan pikin worku no ben drifi $k o n$ leti na en fesi.

Busi ben kon tron wan spukuspuku dungru

5 hipi; yu ben kan yere fa dowwatra ben $e$ dropu fadon na den wiwiri, nèlek na dyumbi ben e waka na tapu den finga-ede.

Liba ben e lon, fu di yu sabi taki a $e$ lon. Noso yu ben sa prakseri nomo taki na wan

10 bigi spikri, di sontron na son presi ben e proyproy sorfrusorfru, te wan safri winti saka kon te na ondrosey.

Ma ini safsafu tiri disi, nèlek na now fosi grontapu ben e bigin, wan gitar

15 ben bigin prey èn wantu yonkman ben $e$ singi na singi di wan fu den ben meki so dyonsrodyonsrode.

A singi ben e ferteri fa pranpran liba ben kon krasi, fa a opo mofo swari a

20 lay, bifo boto doro Posu.

A lay di ben musu yepi tyari a moni kon, fu bow wan oso gi wan lobilobi uma. Sonte, efu munkenki no ben skèyn so sari, a singi ben sa de wan tra fasi.

25 Ofu kande sani waka so fu di owrukuku ben kari, bika te owrukuku kari, dan alaten yu prakseri e dray go na a dungru fu dede.

"Suma no abi wroko meki a kon!" $\mathrm{Na}$ so a

30 fowru disi e kari. $\mathrm{Na}$ so mamá ben leri fu granmamá, èn na so a ben ferteri en pikin baka.

Ėn na baka kari fu owrukuku alaten wan sari sani ben e pasa.

35 A no ala mofoneti Luti ben e tyari en gitar kon. Dan den no ben e singi someni, ma Dorsi ben e ferteri tori. Te en sten ben kon na fesi, ala trawan ben e tapu. Den ben lobi fa den skin ben e gro, te

40 Dorsi sten ben e saka gwe te wan frede tori ben e kon. Te na tori ben kon span letleti, den ben e fergiti fu hari bro.

Ma a watra ben e tan naknaki nomonomo na sey den kruyara na lanpresi.

\section{The owl had cried}

Maybe the moon would not have shone so sadly that night, if a small cloud had not drifted (so that it) came right in its face.

The forest had come to turn into a spooky dark heap; you could hear how the dewdrops were dripping down on the leaves, as if it was ghosts that were walking on tiptoe.

The river was running, because you know that it runs. Otherwise you would have thought that it was a big mirror that sometimes in some places unfolded in a silvery way when a soft wind came down to come below.

But in this soft silence, as if it was now first that the world was beginning, a guitar had begun to play, and one or two youths were singing the song that one of them had made just now.

The song told how suddenly the river had become wild, how it opened its mouth to swallow the load, before the boat arrived in Posu. The load that should have helped to bring the money to build a house for a beloved woman. Maybe, if the moon had not shone so sadly, the song would have been a different way. Or perhaps things went that way because the owl had cried, because when the owl has cried, then always your thoughts turn to go to the dark of death.

"Who has no work, let him come!" It is so that this bird cries. It is so that mother had learn$e d$ it from grandmother, and it is so that she had told it her children again.

And after the hooting of the owl always a sad thing happened.

It was not every night that Luti brought his guitar with him. Then they did not sing so much, but Dorsi would tell stories. When his voice had become audible, all the others would stay silent. They loved it how their skin grew (i.e. the flesh crept) when Dorsi's voice fell when a scaring story came. When the story had become right thrilling, they forgot to draw breath. But the water kept touching invariably the sides of the canoes at the mooring place. 
45 Dya den yonkman ben kan luku go na liba, ma den ben kan si tu den rediredi kokolampu faya fu den pikin masanga.
Here the youths could watch towards the river, but they could see too the red lights of the oil lamps from the little huts.

\section{Commentary}

line 3: $k$ on is a serial verb.

line 6: fadon is a serial verb.

$n a$ introduces the cleft construction. One would have expected a past tense, but this form of BE is 'tenseless'.

line 9: $n a$ : may be a present tense, since 'sequence of tenses' is very limited in Sranan.

line 12: $k$ on is a serial verb.

line 13: tenseless $n a$ of the cleft construction.

line 15: ben bigin prey: the past perfect fits in well, but so does the simple past 'began'. It is impossible to know which the author had in mind. If it was the simple past, we have an instance of the subvariety of System A where the simple past has ben.

line 19: swari is a serial verb.

line 21: tyari is a serial verb.

line 22: kon is a serial verb.

line 27: $g o$ is a serial verb.

line 34: ben e pasa: the durative past 'happened' or 'would happen' is quite appropriate. But, as mentioned in Section 1.2 above, one might wish to read an underlying ben-ben-e, i.e. the past perfect of the durative. This would be against the rules for underlying structures as defined in Section 1.2, and would require a multiple tense analysis.

line 35: a no from underlying $a$ no $00 B E$. S-3 gives $n a$ for BE. S-4 deletes the pronoun $a$ ('it'). S-5 changes no na into $a$ no.

line 36: kon is a serial verb.

line 40: gwe is a serial verb, 'so that it went away', i.e. 'all the way down'. line 45: $g o$ is a serial verb, meaning 'towards'.

Received 6 November 1981

Revised version received

19 February 1982
Philosophy Institute

Nijmegen University

Aquinostraat 3

Nijmegen

Holland

\section{Notes}

1. I am grateful to Rigoni de Abreu-Muller, Lillian Adamson, John Defares, and many others for their help and understanding while I was trying to get a coherent survey of 
the verbal forms of Sranan. I am also indebted to Salikoko Mufwene, Herman Wekker, Jan Voorhoeve, André Kramp, Harry van der Hulst, and others, for their critical comments.

2. The emancipatory aspect of Sranan studies should not be underestimated. Although Sranan is the native language of about half the population of Surinam and a second language for almost the entire other half, it still suffers from social disrespect, especially compared to Dutch. Sranan may still not be used in the schools, where Dutch is the only medium language allowed. The result is often a profound linguistic insecurity with respect to both Sranan and Dutch, quite apart from the many other negative effects of obligatory elementary school education in a foreign language. Sranan studies may be useful in helping to establish full social respect for the language and the culture it represents. For an authentic report on the status of Sranan in Surinam society, see Eersel, 1971.

3. My earlier paper (1981a) is based on the same data and the same distinctions, except for a few minor additions in the paradigm of the verb $\mathrm{BE}$ (which is so complex that absence of variation would be most amazing). I was often puzzled by the amount of variation in data and judgèments, which made this research difficult to pursue. The large amount of variation and uncertainty is no doubt due to the fact that 'the system is in change' (Eersel, 1971: 322), and also to the lack of a recognised standard form of Sranan, taught in schools and practised in writing.

4. The spelling adopted follows the rules given in Seuren, $1981 \mathrm{~b}$ for formal and informal spelling of Sranan words and sentences. In general, formal spelling is used, with the exception of the informal spellings $k b a$ (formal kabá), ppa (formal papá) and mma (formal mamá).

5. Kba (from Spanish-Portuguese acabar 'finish') can be used in two ways: as a verb, followed by an infinitive, meaning 'finish': mi kba nyan 'I have finished eating', or as an adverb, meaning 'already', in which case it stands at the end of the sentence: mi nyan $k b a$ 'I have eaten already'. It is the obvious counterpart of don (from English done) in the neighbouring Guyanese Creole. Bickerton (1975: 41) states that 'there is no mention of either don or any functional equivalent in the published literature on Sranan'. This is correct. Voorhoeve (1957), in particular does not mention it. Bickerton (1975: 54) wonders if 'don exists in Sranan as a very rare or marginal form', but there can be no doubt that the very common $k b a$ is the functional equivalent looked for in Sranan. Apparently, $k b a$ has remained Spanish-Portuguese in Sranan, but has been relexified into English-based don in the Creole of Guyana.

6. This sentence was observed during normal conversation by John Defares.

7. Voorhoeve (1962: 37) gives: mi no de wan temreman ('I am not a carpenter'). Hein Eersel informs me that this variant does exist but is rather 'acrolectal' (if that term may be used where there is no continuum). The genuine Sranan form is mi a no (wan) temreman.

8. $E n$ is the normal non-subject (inflected) form of $a$. With strong emphasis or contrast it can also be used as the subject pronoun for 'he/she/it'. In (1lk) and (1lu), however, en is used without any special emphasis or contrast.

9. Not unlike the extravagant use of French words in Dutch in the 18th and early 19th centuries.

10. Cp. McCawley (1971), Lyons (1977: 677-690), for the deictic character of tenses.

11. See Seuren, 1981a for a more principled and more formal account of the semantics of the durative aspect. There, durativity is analysed as quantification over a series of moments, not a single moment, by $\mathrm{t} 2$. The kind of quantification made by $\mathrm{t} 2$ is thus transferred to the main verb as a [+durative] or [-durative] feature. 
12. The formal specification of the finite verb position is as follows:

$$
\mathrm{X}-\mathrm{NP}-(n o)-\mathrm{vp}[\mathrm{t} \mathrm{l}-\mathrm{t} 2 \ldots-\mathrm{Y}]-\mathrm{Z}(\mathrm{X}, \mathrm{Y}, \mathrm{Z} \text { may be null). }
$$

13. I thank Hein Eersel for drawing my attention to the double form of question formation in Sranan.

14. I owe this observation to Hein Eersel and August Duttenhofer.

15. See Seuren, 1981a for a much more detailed theory of the grammatical (deep structure) treatment of $e$, ben and $o$ as verbs.

16. (27c) and (27d) are taken from a children's story by Afanti. (27e) was observed by Mark Sebba.

17. Cp. Keenan, 1979: 175: 'However, given the similarity in function-argument structure between transitive verbs and their Objects and Prepositions and their Objects it is perhaps not surprising that transitive verbs can historically become reduced to function as dependent forms, i.e. Prepositions'.

\section{References}

Bailey, B. L. (1966). Jamaican Creole Syntax: A Transformational Approach. Cambridge: Cambridge University Press.

Bickerton, D. (1975). Dynamics of a Creole System. London: Cambridge University Press.

DeCamp, D. (1971). Toward a generative analysis of a Post-Creole Speech Continuum. In

D. Hymes (ed.), Pidginization and Creolization of Languages, 349-370. Cambridge: Cambridge University Press.

Eersel, Ch. H. (1971). Varieties of Creole in Suriname. Prestige in choice of language and linguistic form. In D. Hymes (ed.), Pidginization and Creolization of Languages, 317-322. Cambridge: Cambridge University Press.

Herlein, J. D. (1718). Beschrijvinge van de Volk-plantinge Zuriname. Leeuwarden: Meindert Injema.

Hymes, D. (ed.) (1971). Pidginization and Creolization of Languages. Cambridge: Cambridge University Press.

Keenan, E. L. (1979). On surface form and logical form. In Braj B. Kachru (ed.), Linguistics in the Seventies: Directions and Prospects, 163-203. Special Issue of Studies in the Linguistic Sciences. Department of Linguistics, University of Illinois.

Koefoed, G. and May, R. (1980). Motieven van taalkeuze in Suriname. In G. Geerts and A. Hagen (eds), Sociolinguistische Studies I. Bijdragen uit het Nederlandse Tualgebied, 257-285. Groningen: Wolters-Noordhoff.

Lyons, J. (1977). Semantics. Cambridge: Cambridge University Press.

McCawley, J. D. (1971). Tense and time reference in English. In C. J. Fillmore and D. T. Langendoen (eds), Studies in Linguistic Semantics, 96-113. New York: Holt, Rinehart and Winston.

Mufwene, S. S. (1980). Observations on time reference in Jamaican and Guyanese Creoles. Paper read at the Third Biennial Conference of the Society of Caribbean Linguistics. Aruba, 21-23 September 1980.

Reichenbach, H. (1947). Elements of Symbolic Logic. London: Macmillan.

Rigter, G. H. (1980a). Time diagrams and rules for tense and perfect in English. In W. Zonneveld and F. Weerman (eds), Linguistics in the Netherlands 1977-79, 411-458. Dordrecht: Foris.

-(1980b). Laying the ghost of times past. Linguistics 18-9/10, 849-870.

Schuchardt, H. (1914). Die Sprache der Saramakkaneger in Surinam. Verhandelingen der 
Koninklijke Akademie van Wetenschappen te Amsterdam, Afdeeling Letterkunde, Nieuwe Reeks, deel XIV, No. 6. Amsterdam: Müller.

Seuren, P. A. M. (1981a). The auxiliary system in Sranan. In F. Heny and B. Richards (eds), Proceedings of the Fourth Groningen Round Table Conference on Auxiliaries, 4-8 July 1980. Dordrecht: Reidel.

- (1981b). De spelling van het Sranan: een diskussie en een voorstel. Sociaal-Ekonomisch Tijdschrift Suriname (SETS), 2.1 (in press).

Voorhoeve, J. (1957). The verbal system in Sranan. Lingua VI. 4, 374-396.

-(1962). Sranan Syntax. Amsterdam: North-Holland.

- (1973). Historical and linguistic evidence in favour of the relexification theory in the formation of Creoles. Language in Society 2, 133-145.

Voorhoeve, J. and Lichtveld, U. M. (1975). Creole Drum. An Anthology of Creole Literature in Surinam. Caribbean Series 15. Newhaven, London: Yale University Press. 